\title{
The Palliative Effects of System Justification on the Health and Happiness of Lesbian, Gay, Bisexual, and Transgender Individuals
}

Personality and Social

Psychology Bulletin

2019, Vol. 45(3) 372-388

(C) 2018 by the Society for Personality

and Social Psychology, Inc

Article reuse guidelines:

sagepub.com/journals-permissions

DOI: 10.1 I77/0|46/67218785I56

journals.sagepub.com/home/pspb

(SAGE

\author{
Alexandra Suppes', Jaime L. Napier', \\ and Jojanneke van der Toorn ${ }^{2,3}$
}

\begin{abstract}
Across three studies, we examine the correlates of subjective well-being and mental and physical health among members of a historically disadvantaged group, namely, lesbian, gay, bisexual, and transgender (LGBT) individuals. Results show those who minimize (vs. acknowledge) the extent to which their group is the target of discrimination report better well-being across myriad indicators (Studies I-3). We also demonstrate that this effect is mediated by perceived system fairness (Study I); holds above and beyond internalized homonegativity (Studies I and 3) and ingroup identification (Studies 2-3); and is true regardless of whether individuals reside in hostile or accepting environments (Study 2), and regardless of whether individuals had personally experienced discrimination (Study 3). For some indicators (namely, body mass index [BMl], social well-being, self-esteem, depression, and mental illness diagnosis), the relationship between minimization of discrimination and well-being was stronger among those who had frequent (vs. rare) discriminatory experiences.
\end{abstract}

\section{Keywords}

well-being, health, system justification, LGBT, discrimination

Received August 23, 2017; revision accepted June 5, 2018

Lesbian, gay, bisexual, and transgender (LGBT) individuals are subject to severe hostility (Waters, Jindasurat, \& Wolfe, 2016), and this has deleterious effects on their psychological well-being and mental and physical health (Hatzenbuehler, 2014; Meyer, 2003). Although prejudice and discrimination against members of the LGBT community is pervasive, there is substantial variation in the extent to which people acknowledge (vs. downplay) the extent to which their group is the target of societal hostility. In the current research, we examine the perception of discrimination among LGBT individuals and its relation to well-being. Specifically, leveraging insights from system justification theory, we posit that minimizing the extent to which members of their group are targets for discrimination and hostility serves a "palliative function" for sexual minorities. Across three studies, using highly diverse samples of members of the LGBT community, we test the prediction that minimizing the problem of group-directed discrimination, which is positively related to perceptions of system fairness (Study 1), is a robust predictor of subjective well-being and better mental and physical health (Studies 1-3), even (and sometimes especially) for those who have personally experienced discrimination (Study 3).

\section{Discrimination Against LGBT Individuals}

While the legal and cultural landscape for LGBT individuals in America is transforming, a deep thread of homophobia and discrimination persists. Sexual minorities face pervasive hiring discrimination (Tilcsik, 2011) and are the targets of hate-related crime, including homicide, and harassment by police officers (Waters et al., 2016). There is no federal law that prohibits discrimination based on sexual orientation in America, and "gay conversion" therapy, long reputed by the American Psychological Association as unethical and psychologically harmful, remains a legally sanctioned practice in 45 out of the 50 U.S. States (Potok, 2016).

'New York University Abu Dhabi, United Arab Emirates

${ }^{2}$ Leiden University, The Netherlands

${ }^{3}$ Utrecht University, The Netherlands

\section{Corresponding Author:}

Alexandra Suppes, Department of Psychology, New York University Abu Dhabi, Saadiyat Campus, P.O. Box 129188, Abu Dhabi,

United Arab Emirates.

Email: acs22@nyu.edu 
Even the earliest psychological theories posited that being a victim of prejudice exerts negative effects on mental and physical health (McLean, 1946), a point that continues to be supported by contemporary data (e.g., Cochran, Sullivan, \& Mays, 2003; Hatzenbuehler, 2014). Among members of disadvantaged groups, personal experiences with discrimination are linked to multiple indicators of poorer mental and physical health across multiple indicators, including psychological distress (Sellers \& Shelton, 2003), lower self-esteem and feelings of mastery (Williams, Neighbors, \& Jackson, 2003), heightened stress responses (Pascoe \& SmartRichman, 2009), increased frequency of unhealthy behaviors (and lower levels of healthy behaviors; Pascoe \& SmartRichman, 2009), and depression (Schmitt, Branscombe, Postmes, \& Garcia, 2014).

LGBT individuals have relatively higher rates of depression and psychiatric disorders compared with their heterosexual counterparts (Cochran et al., 2003), and the likelihood of mental and physical health problems is increased among those who harbor negative attitudes about their sexual orientation ("internalized homonegativity"; Herek, Gillis, \& Cogan, 2009; Lick, Durso, \& Johnson, 2013; Meyer, 2003), and among those who live in intolerant environments (Hatzenbuehler, 2014). Nevertheless, the psychological profiles of the majority of sexual minorities are normal and healthy (e.g., Cochran et al., 2003; Meyer, 2003), which raises the question of what psychological mechanisms people might employ that buffer themselves from the otherwise toxic effects of stigmatization.

Previous researchers have highlighted ingroup identification as one potential coping strategy, arguing that experiencing discrimination should lead to high identification with the stigmatized group, which, in turn, can provide a sense of belonging in the face of societal exclusion (e.g., Branscombe, Schmitt, \& Harvey, 1999; Schmitt, Branscombe, Kobrynowicz, \& Owen, 2002). According to this "rejectionidentification model," the salience of experiencing discrimination not only is psychologically deleterious but also promotes group identification, which minimizes (to some extent) the direct negative impact of this devaluation on well-being.

Among the handful of studies that have examined group identification among LGBT individuals, results have shown that group identification is positively associated with reports of experiencing discrimination (Fingerhut, Peplau, \& Gable, 2010) and with subjective well-being (Fingerhut et al., 2010; Kertzner, Meyer, Frost, \& Stirratt, 2009), in line with the rejection-identification model. However, at least one study also found that the perception of the group's societal stigma, more generally, was more strongly related to subjective wellbeing than having personally experienced discrimination, such that LGBT individuals who perceive their group to be the target of relatively little (vs. much) discrimination report fewer depressive symptoms (Fingerhut et al., 2010).
This finding highlights an important distinction between being the target of discrimination on an individual/interpersonal level, and the perception that one's group is the target of discrimination on a societal level (Bourguignon, Seron, Yzerbyt, \& Herman, 2006; Crosby, 1984; Schmitt et al., 2014). Most theories about the impact of societal stigma focus on individuals' personal encounters with discriminatory treatment (e.g., Branscombe et al., 1999; FeldmanBarrett \& Swim, 1998; Major et al., 2002). However, there are reasons to believe that perceptions of how society views (and treats) the ingroup more generally-regardless of one's own experiences with prejudice - could also be related to well-being for members of disadvantaged groups. For instance, among Black women, the awareness that others hold negative stereotypes about their group (independent of whether or not they internalized the stereotypes) is associated with mental health illness, less self-care, and more substance abuse (Jerald, Cole, Ward, \& Avery, 2017). Insofar as societal-level hostility (in the form of negative stereotypes or discrimination) is a threat to the perceived fairness of society, those who minimize the extent to which their group is the target of this hostility are likely better able to maintain a belief that the system, overall, is fair and legitimate, and this could, in turn, promote subjective well-being.

\section{The Palliative Function of Perceiving Fairness}

A research program on system justification theory (Jost, Banaji, \& Nosek, 2004) has demonstrated that believing that society is fair provides a sense of order, certainty, meaning, and security, and thus can serve a palliative function insofar as it reduces moral outrage (Wakslak, Jost, Tyler, \& Chen, 2007) and promotes life satisfaction (Napier \& Jost, 2008; Napier, Thorisdottir, \& Jost, 2010). More generally, the belief that the world is a just place has been referred to as a "fundamental delusion" (Lerner, 1980) because it is a crucial component of psychological well-being. Researchers have shown that people who more strongly believe that the world is fair have more positive affect, less depression, feel less lonely, are more optimistic, and are more effective at coping with stress (see Dalbert, 2001, for review).

For members of stigmatized groups, such as LGBT individuals, the perception that the social hierarchy is legitimate, and thus so is one's low place on the social totem pole - that is, perceiving the world as fair at the expense of the self-is likely to hurt, not bolster, well-being, as evidenced by the research on the negative health effects of internalized stigma (Lick et al., 2013). However, perceiving the system as legitimate may not always manifest as the internalization of societal stigma. For instance, in a sample of sexual minorities in Chile, the belief that the overarching system is fair was negatively related to depression and anxiety, whereas internalized homonegativity was positively related (Bahamondes-Correa, 
2016). This suggests that at least some sexual minorities are able to perceive the system as legitimate (and reap the psychological benefits from doing so) without internalizing their low societal status.

Another way to maintain the belief that the world is fairand one that may be more pervasive (e.g., Norton \& Ariely, 2011) - is to simply ignore evidence that it is not. Studies have shown, for instance, that people who think the world is fair are less likely to perceive discrimination, and this, in turn, promotes psychological well-being. For instance, older adults with high (vs. low) just-world beliefs were less likely to think that age discrimination was prevalent in America (Lipkus \& Siegler, 1993), and prisoners with high (vs. low) just world beliefs were less likely to believe that they experienced discrimination in their legal proceedings and, consequently, were better able to cope with their anger (Dalbert \& Filke, 2007).

\section{The Current Work}

Across three studies, we directly test the proposition that among members of a severely devalued group-namely, LGBT individuals - those who minimize the extent of discrimination directed toward their group are happier and healthier than those who do not. We refer to this as the "palliative" (rather than curative) effect of system justification because although "positive illusions" can promote mental health for the individual (Taylor \& Brown, 1988), they also serve to maintain societal ills (e.g., inequality and oppression).

Our system justification account suggests that beliefs about discrimination on the societal level should uniquely impact psychological well-being, regardless of an individual's personal experiences with discriminatory treatment (Paradies, 2006). Although the distinction between perceiving one's self versus perceiving one's group as a target of discrimination is theoretically important (Crosby, 1984; Schmitt et al., 2014), it has not always been made empirically, with researchers sometimes combining both constructs into a general measure of "ingroup disadvantage" (e.g., Schmitt et al., 2002). Thus, one aim throughout our studies is to focus specifically on people's perceptions of discrimination toward their group more generally. Given that societal discrimination against sexual minorities is overt, pervasive, and legally sanctioned (in most states and at the federal level), it seems impossible for LGBT individuals not to acknowledge their group's disadvantage to some extent. For this reason, although few individuals will outright deny that their group is a target for discrimination, we expect that those who downplay (or minimize) the problem will report better subjective well-being compared with those who acknowledge it.

In Study 1, we measure three potential manifestations of system justification - namely, internalization of homonegativity, distancing from the group (i.e., group-directed homonegativity), and the minimization of LGBT discrimination - and examine their relations to subjective well-being in a sample of gay and bisexual men. We predict that, above and beyond the (presumably negative) effects of internalized and groupdirected homonegativity, the minimization of societal discrimination toward the LGBT community will be associated with better subjective well-being, and this will be accounted for by perceived system fairness - that is, those who perceive relatively low (vs. high) levels of LGBT discrimination will perceive the system to be fairer, and this will be associated with better well-being. In Studies 2 and 3, using large, racially and ethnically diverse samples of members of the LGBT community, we examine the associations between minimization of LGBT discrimination and group identification with indicators of mental and physical health. We predict that, above and beyond the effects of ingroup identification, the perception of low (vs. high) levels of discrimination against the LGBT community will be associated with higher wellbeing among members of this group, even for those living in places that are especially hostile toward sexual minorities (Study 2), and even for those who have had direct, personal experience with discrimination (Study 3).

\section{Study I}

Sexual minorities who are motivated to perceive the system as fair appear to internalize society's values (BahamondesCorrea, 2016; Pacilli, Taurino, Jost, \& van der Toorn, 2011), which could manifest as derogating the self (internalized homonegativity) or derogating the ingroup (group-directed homonegativity), which, in turn, should be negatively associated with subjective well-being. Here, we examine how the minimization of LGBT discrimination could be another potential route to perceiving system fairness. Unlike internalization of inequality, minimizing the extent of the group's disadvantage allows people to view the system as fair without derogating the self or group, which should be positively associated with subjective well-being, at least insofar as system justification serves a palliative function.

In this first study, we measured negative attitudes toward the self (internalized homonegativity) and the group (groupdirected homonegativity), perceptions of societal discrimination toward the LGBT community, and system fairness in a sample of gay and bisexual men. Our focal hypotheses are that (1) above and beyond the effects of internalized and group-directed homonegativity, perceptions of low (vs. high) levels of group-directed discrimination will be associated with greater subjective well-being and (2) this relationship will be mediated by perceptions of system fairness.

\section{Method}

Procedure. We recruited men who have a sexual preference for men to participate in an online survey about partner preferences through Amazon's Mechanical Turk. Of the 151 respondents, nine reported that they were female, and nine 
male respondents reported they sexually prefer "exclusively" or "mainly" women, yielding a final sample of 133 men $\left(M_{\text {age }}=28.24, S D=9.81\right)$ who sexually prefer "exclusively men" $(n=70)$, "mainly men" $(n=47)$, or "men and women" $(n=16) .{ }^{1}$ A post hoc power analysis conducted with $\mathrm{G}^{*}$ Power (Faul, Erdfelder, Lang, \& Buchner, 2007) indicated that this sample size is sufficient to capture a moderate effect size of $r=.30$ with power of $95.0 \%$.

The sample was predominantly White $(69.2 \%)$ and educated (56.4\% with a university degree). After consent was obtained, participants rated potential partners as part of a separate study. Next, participants responded to a questionnaire assessing the perceived stigma among sexual minorities (Sandfort, 1997), with response options ranging from $1=$ extremely disagree to $7=$ extremely agree. We categorized these items into measures of (a) internalized homonegativity (e.g., "If someone offered me the chance to become completely heterosexual, I would take it with both hands"; four items; $\alpha=.83 ; M=2.27, S D=1.29$ ); (b) group homonegativity (or denigrating the group, for example, "When I see certain gays and lesbians on television, I don't want to group myself with them"; four items; $\alpha=.75 ; M=3.39, S D=$ 1.39); and (c) minimization of LGBT discrimination (e.g., "Gays and lesbians who claim they are being discriminated against are overreacting"; three items; $\alpha=.54 ; M=3.00, S D$ $=1.25$ ). See supplemental materials for full study details.

Perceived system fairness was assessed with an eightitem scale (Jost \& Kay, 2005; for example, "In America, everyone has a fair shot at wealth and happiness"), with responses recorded on a 1 to 7 scale $(\alpha=.80 ; M=3.57, S D$ $=1.07)$. Subjective well-being was assessed with nine items, measured on a 1 to 5 scale (e.g., "To what extent do you find your life to be meaningful?" $\alpha=.88 ; M=3.53, S D=0.78$ ). We also included adjustments for demographic variables known to be associated with life satisfaction (Napier \& Jost, 2008), namely, race (White vs. "other"), education (college degree vs. not), age (mean-centered), the quadratic effect of age, political orientation (11-point scale, mean-centered), and religiosity (7-point scale; mean-centered).

\section{Results}

Table 1 lists the bivariate correlations among the focal variables. We conducted a linear regression model predicting subjective well-being with the two homonegativity measures and discrimination minimization in the first step and system fairness in the second step, adjusting for demographic variables. As can be seen in Table 2 and illustrated in Figure 1, in the first step $\left(R^{2}=.17\right)$, internalized homonegativity was negatively related to subjective well-being, whereas minimization of discrimination was positively related; groupdirected homonegativity and subjective well-being were unrelated. In Step $2\left(R^{2}=.24\right)$, we find that system fairness is positively associated with subjective well-being, and that once this is included in the model, the association between
Table I. Correlations Among Focal Variables (Study I, N = I33).

\begin{tabular}{llllll}
\hline & & 1 & 2 & 3 & 4 \\
\hline 1 & Subjective well-being & - & & & \\
2 & Internalized homonegativity & -.233 & & & \\
3 & Group homonegativity & -.084 & .520 & & \\
4 & Minimization of discrimination & .137 & .414 & .303 & \\
5 & System fairness & .278 & .192 & .148 & .447 \\
\hline
\end{tabular}

Note. $p<.05$ for bolded coefficients.

minimization of discrimination and subjective well-being is reduced and no longer reliable; the associations between internalized homonegativity and group-directed homonegativity with subjective well-being were unchanged. A bootstrapping procedure with 5,000 bootstraps confirmed that the system fairness significantly mediated the relationship between minimization of discrimination and well-being, $b=$ $.07, S E=0.03$, bias corrected $95 \%$ confidence interval $=$ $[0.02,0.14]$.

\section{Discussion}

Results from our first study are consistent with the prediction that minimizing the disadvantage of a stigmatized ingroup can promote subjective well-being because of the systemjustifying function it serves. We found that, among gay and bisexual men, minimization of discrimination directed toward sexual minorities in general was positively associated with subjective well-being, and perceptions of system fairness significantly mediated this relationship.

The findings from this study are notable for two reasons. First, there was a significant association between system fairness and subjective well-being in this sample of gay and bisexual men, supporting the notion that system justification can serve a palliative function even among members of this stigmatized group (see also, Bahamondes-Correa, 2016). Second, minimization of discrimination (and not homonegativity toward the self or group) appears to be the system-justifying mechanism that promotes subjective well-being among members of stigmatized groups. Internalized homonegativity was negatively associated with well-being, and this was not at all related to perceptions of system fairness. Minimization of LGBT discrimination, by contrast, was positively associated with well-being, and this effect was accounted for by perceptions of system fairness, presumably because downplaying the hostility directed toward the ingroup allows people to maintain a belief that the world is just.

Although it is beyond the scope of this article, this leads to interesting questions regarding the ways in which the motivation to justify the system is likely to manifest among members of disadvantaged groups. Previous research has focused on how system-justifying motives might lead sexual minorities to internalize their social stigma, but empirical investigations 
Table 2. Coefficients (SE), $p$ Values, and $95 \%$ Cl Limits From a Stepwise Linear Regression Model Predicting the Subjective Well-Being of Gay and Bisexual Men (Study I; N = I33).

\begin{tabular}{|c|c|c|c|c|c|c|}
\hline & \multicolumn{3}{|c|}{ Step I } & \multicolumn{3}{|c|}{ Step 2} \\
\hline & $b(S E)$ & $p$ & $\mathrm{Cl}$ & $b(S E)$ & $p$ & $\mathrm{Cl}$ \\
\hline Intercept & $3.4 I(0.13)$ & $<.001$ & {$[3.16,3.67]$} & $3.40(0.12)$ & $<.001$ & {$[2.04,3.19]$} \\
\hline Internalized homonegativity & $-0.21(0.06)$ & .002 & {$[-0.33,-0.08]$} & $-0.21(0.06)$ & .001 & {$[-0.33,-0.09]$} \\
\hline Group homonegativity & $0.01(0.06)$ & .916 & {$[-0.11,0.12]$} & $0.02(0.06)$ & .725 & {$[-0.09,0.13]$} \\
\hline Minimization of discrimination & $0.15(0.07)$ & .035 & {$[0.01,0.29]$} & $0.06(0.06)$ & .368 & {$[-0.09,0.21]$} \\
\hline System fairness & & & & $0.22(0.07)$ & .004 & {$[0.07,0.36]$} \\
\hline
\end{tabular}

Note. Model includes adjustments for age, age squared, race (White vs. not), education (college degree vs. not), political orientation, and religiosity. For Step $\mathrm{I}, R^{2}=.17$; for Step $2, R^{2}=.24$. Cl = confidence interval.

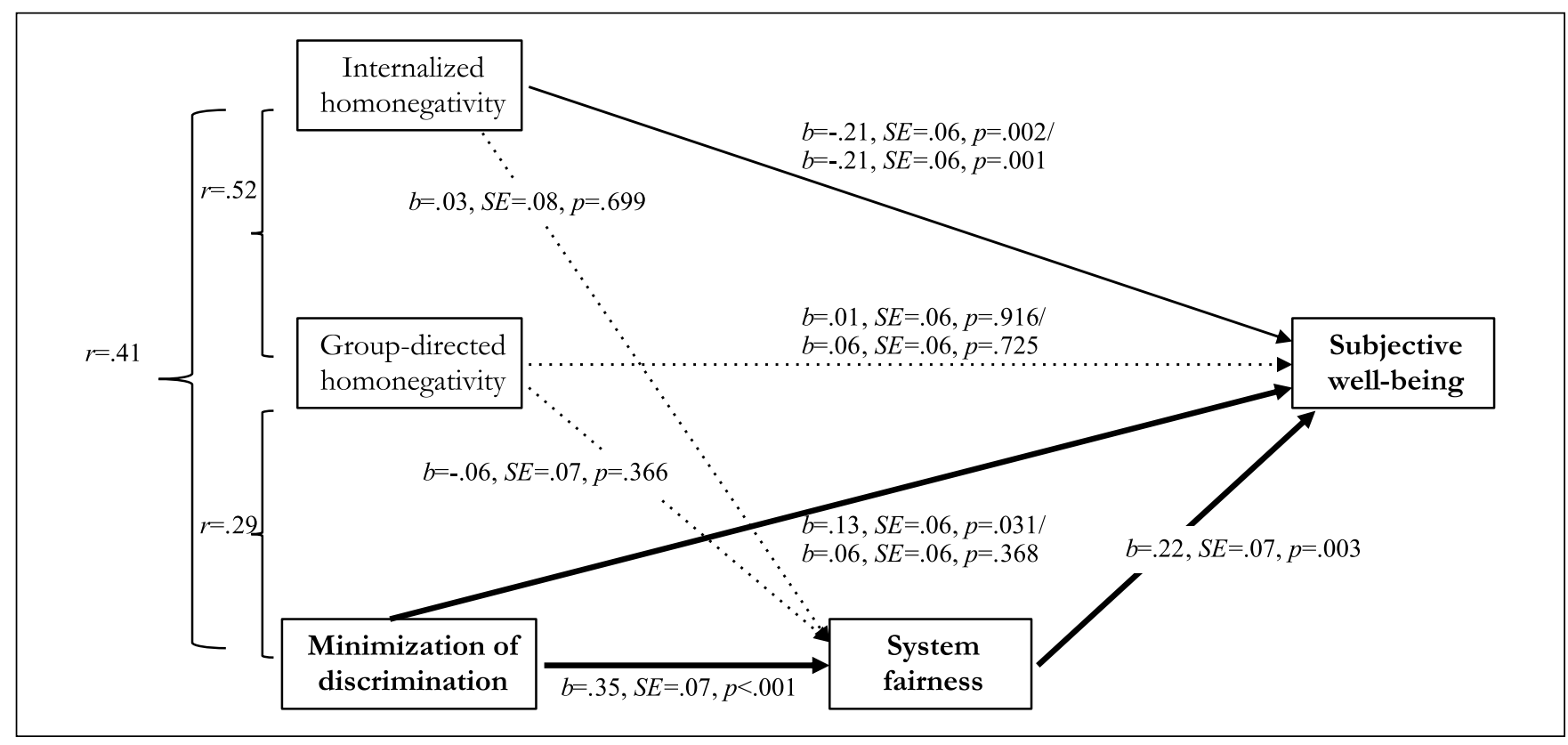

Figure I. Perceptions of system fairness significantly mediate the association between minimization of LGBT-directed discrimination and subjective well-being among gay men $(N=133$, Study I).

Note. Solid lines represent significant associations; dotted lines represent nonsignificant association. LGBT = lesbian, gay, bisexual, and transgender.

have revealed only modest correlations between internalized homonegativity and system fairness perceptions (i.e., $r=.18$, Pacilli et al., 2011; $r=.11$, Bahamondes-Correa, 2016). In our sample, too, we found that the perception of system fairness was only weakly correlated with internalized homonegativity, $r(131)=.192, p=.027$, and with group-directed homonegativity, $r(131)=.148, p=.090$, whereas the relationship between system fairness perceptions and minimization of discrimination was much stronger, $r(131)=.447, p<.001$. This suggests that beliefs that manage to mask the conflict between self-, group-, and system-justifying motives (such as downplaying system-level discrimination or otherwise reframing the societal hierarchy) might be the most successful in promoting a positive view of the system for members of disadvantaged groups.

There are several limitations of this study that we address in Studies 2 and 3. First, the sample was fairly small and homogeneous. It is possible that this predominantly White, male sample represents the population that is most likely to benefit from justifying the system insofar as they are otherwise privileged (their sexual orientation notwithstanding). Second, it is conceivable that people's perceptions of societal LGBT discrimination are influenced by their environment, and that those who live in more gay-friendly places both perceive less societal discrimination toward LGBT people and have better subjective well-being (Hatzenbuehler, 2014). Although we did find that, consistent with our system justification account, system fairness perceptions mediated our effect, it is nonetheless conceivable that the relationship between minimization of societal discrimination and subjective well-being is, at least in part, due to variance in exposure to discrimination. In Study 2, we tackle this issue by assessing the level of discrimination in the participants' environment using a state-level index of LGBT tolerance. We also 
examine how group identification relates to mental and physical health in LGBT individuals. Research suggests that identification with a stigmatized group should promote subjective well-being because it provides a sense of belonging in the face of societal exclusion (e.g., Branscombe et al., 1999). We posit that ingroup identification and system justification (in the form of the minimization of discrimination) are two distinct and non-conflicting "routes" to subjective wellbeing among members of stigmatized groups.

\section{Study 2}

We analyze data from a large, national survey of sexual minorities living across the United States to examine the associations between minimization of group-directed discrimination and three indicators of well-being, namely, subjective well-being, self-reported physical health, and body mass index (BMI), above and beyond group identification and state-level LGBT hostility.

Based on previous research, we expected that those with strong group identification (Branscombe et al., 1999) would report better subjective well-being and physical health and lower BMI. Because social identity theory posits that group identification serves to protect well-being in the face of rejection, we also tested for an interaction between group identification and state-level LGBT acceptance to examine whether the relationship between identification and wellbeing is especially strong among those living in states where they are more (vs. less) vulnerable to discriminatory treatment.

Based on our own theorizing, we predicted that, above and beyond the positive effects of ingroup identification, those who minimize the extent to which their group is the target of discrimination will report higher subjective wellbeing, better physical health, and lower weight, and that this will be true even for those living in relatively hostile (vs. accepting) states.

\section{Method}

Participants and procedure. We used data from The Social Justice and Sexuality Survey, which interviewed a sample of 4,953 Americans who identify as sexual or gender minorities (see Battle, Pastrana, \& Daniels, 2013). Between January and December 2010, respondents completed a self-administered questionnaire, available in both English and Spanish. Participants were recruited by venue-based sampling, snowball sampling, and online sampling, and through community organizations.

Because we were interested in LGBT participants, we excluded respondents who identified as both heterosexual and cisgender $(n=660)$. In addition, to merge with U.S. state-level data (as we describe below), respondents from the District of Columbia $(n=113)$, Puerto Rico $(n=64)$, and those missing a state $(n=478)$ were excluded from the analyses. This left us with a sample of 3,639 respondents $\left(M_{\text {age }}=35.87, S D=13.04\right)$ which was racially diverse: $23.5 \%$ White, 33.1\% Black, 14.0\% Hispanic/Latina/o, 5.3\% Asian/ Pacific Islander, 2.0\% Native American, $13.5 \%$ multiracial, and $8.5 \%$ "Other." Respondents identified as male $(n=$ $1,756)$, female $(n=1,567)$, gender variant $(n=152$, which includes those who identify as transgender, $n=138$ ), and other or missing $(n=164)$. Regarding sexual orientation, respondents identified as gay $(n=1,481)$, lesbian $(n=970)$, bisexual $(n=459)$, or other/missing $(n=729)$. Among our respondents, $8.3 \%$ identified as non-cisgender. Roughly half of the respondents $(47.6 \%)$ have at least a bachelor's degree. A power analysis (Faul et al., 2007) indicated that this sample size is sufficient to detect a moderate effect size with a power of $99.99 \%$.

Predictor variables. The survey assessed participants' group identification and perceptions of societal discrimination toward LGBT people, but did not measure internalized homonegativity. Group identification was measured with three items, coded on a 6-point scale (e.g., "I feel connected with my local LGBT community"; $\alpha=.75 ; M=4.16, S D=$ 1.28). Three items, coded on a 6-point scale, assessed respondents' perception of LGBT discrimination (e.g., "Homophobia is a problem in my racial or ethnic community"; $\alpha=.73$; $M=2.74, S D=1.29$ ).

Using data from the 2012 American National Election Study $(N=5,914)$, we computed a measure of state-level LGBT acceptance by averaging feeling thermometer ratings of "gays and lesbians" (ranging from $0=$ very cold or unfavorable to $100=$ very warm or favorable $)$ for each state $(M=$ 47.27, $S D=7.76$ ).

Dependent measures. Four items assessed respondents' subjective well-being, measured on a 4-point scale (e.g., "Over the past week, how often have you felt hopeful about the future?" $\alpha=.88 ; M=3.24, S D=0.75$ ). Respondents also reported the state of their physical health (from $1=$ poor to $5=$ excellent; $M=3.64, S D=0.94$ ). Finally, we calculated respondents' BMI, a common metric of weightrelated health, based on self-reported height and weight ( $M$ $=27.41, S D=6.43$ ). BMI between 18.5 and 24.9 is considered "normal weight"; thus, respondents were, on average, overweight (which is typical for an American sample; Ogden, Carroll, Fryar, \& Flegal, 2015). This was true for both male $(M=26.68, S D=5.61)$ and female $(M=28.34$, $S D=7.25)$ respondents.

Adjustment variables. On the person-level, we included several adjustment variables: sex (female vs. male), cis(vs. non-cis) gender, race/ethnicity (Black, Hispanic, and "Other," compared with White), age, age squared, education (7-point scale), religious service attendance (8-point scale), political conservatism (6-point scale), and income (12-point scale). 
Table 3. Correlations Among Focal Variables (Study 2).

\begin{tabular}{|c|c|c|c|c|c|c|c|}
\hline Individual-level $(N=4,273)$ & I & 2 & 3 & 4 & State-level $(N=48)$ & I & 2 \\
\hline I. Minimization of discrimination & - & & & & I. LQBT Acceptance & - & \\
\hline 2. Group identification & -.226 & - & & & 2. Well-being index & $.47 \mathrm{I}$ & - \\
\hline 3. Subjective well-being & .012 & .152 & - & & 3. \% obese & $-.65 I$ & -.610 \\
\hline 4. Health & .031 & .013 & .314 & - & & & \\
\hline 5. Body mass index & $-.07 \mid$ & .028 & .016 & -.252 & & & \\
\hline
\end{tabular}

Note. No respondents resided in Rhode Island or Wyoming, and the state-level variables were not available for the District of Columbia. "LGBT acceptance" is the state average for the 2012 ANES feeling thermometer assessing warmth toward gays and lesbians. Well-Being Index is taken from Gallup Healthways Well-Being Index (2014), and obesity statistics were obtained from the Centers for Disease Control and Prevention (20I5). $p<.05$ for bolded coefficients. LGBT = lesbian, gay, bisexual, and transgender.

Because our dependent measures could be systematically related to other (nonrelevant) aspects of their environment, we also adjusted for state-level well-being, which ranged from 0 to 100 (Gallup Healthways Well-Being Index, 2014). For the models predicting respondents' BMI, we included the percentage of the state population that is obese (Centers for Disease Control and Prevention, 2015) instead of statelevel well-being, but the pattern of results is exactly the same regardless of which variable is included. All continuous variables were mean-centered; dichotomous variables were dummy-coded.

\section{Results}

Table 3 lists the bivariate correlations among the individualand state-level focal variables. For each dependent measure, we conducted a multilevel model (with respondents nested in state) with a random intercept. We estimated the main effects of state-level well-being and LGBT acceptance, group identification and its interaction with state-level acceptance, and minimization of LGBT discrimination and its interaction with state-level acceptance. All models include statistical adjustments for the demographic variables (see supplementary tables for full regression models).

In predicting participants' subjective well-being, as seen in Table 4, there was a main effect of state-level well-being, such that participants' well-being was positively associated with state-level well-being, but no effect of state-level LGBT acceptance above and beyond this. Group identification was positively and significantly related to subjective well-being, but there was no interaction with state-level LGBT acceptance. Finally, as predicted, minimization of discrimination was positively and significantly related to subjective well-being, and this was not qualified by statelevel LGBT acceptance.

For physical health, as shown in Table 4, neither statelevel well-being or LGBT acceptance was a significant predictor. Furthermore, group identification was unrelated to health, and there was no interaction between group identification and LGBT acceptance. As predicted, however, minimization of LGBT discrimination was significantly and positively related to good health, and this was true regardless of the state-level LGBT acceptance, as evidenced by the nonsignificant interaction.

For BMI, as seen in Table 4, there was a main effect of state-level LGBT acceptance, such that participants' BMI was lower in states with higher LGBT acceptance. There was no effect of state-level obesity. Group identification was unrelated to BMI, and the interaction between identification and state-level acceptance was not significant. As predicted, the minimization of societal LGBT discrimination was significantly and negatively related to BMI, such that individuals who tended to minimize discrimination weighed less than those who did not. Results also showed an interaction between minimization of LGBT discrimination and statelevel acceptance. Simple slopes analyses showed that, for those in relatively accepting environments $(+1 S D)$, there was no reliable relationship between minimization of discrimination and BMI, $b=-.13, S E=0.13, p=.342$. For those in more hostile states $(-1 S D)$, by contrast, the minimization of discrimination was negatively and significantly related to BMI, $b=-.62, S E=0.14, p<.001$.

\section{Discussion}

The analysis of a large, racially diverse sample of LGBT individuals living across the United States showed that the minimization of societal discrimination toward the LGBT people is a consistent predictor of happiness, health, and body weight. This was true above and beyond the level of acceptance of sexual minorities in the state where the respondent lives. Thus, even for those living in a relatively hostile environment, the minimization of societal LGBT discrimination is associated with better well-being.

Although prevalence of obesity is regional, the multilevel aspect of our analysis eliminates the possibility that the relationship between minimization of discrimination and BMI is somehow an artifact of the respondents' state. That is, the estimates show that within any given state, those who minimize the extent of LGBT discrimination have lower BMI than those who do not. We also found an interaction between minimization of discrimination and state-level LGBT acceptance in predicting BMI. People who minimized discrimination directed toward the group had lower BMI, and this was 


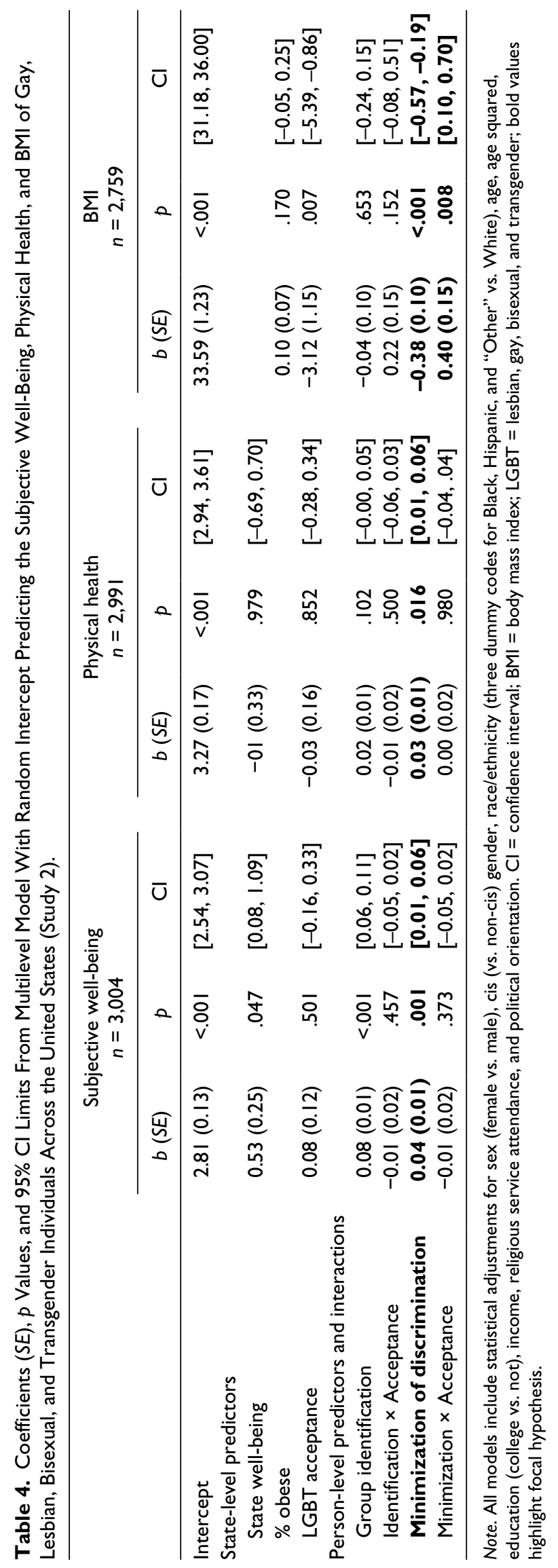


especially true among respondents in states with low (vs. high) levels of LGBT acceptance.

State-level policies, conditions, and norms regarding sexual minorities vary dramatically, and attitudes toward LGBTs are a good indicator of the level of structural stigma (Hatzenbuehler, 2014). Thus, what this multi-level analysis shows is that minimization of discrimination is associated with well-being, even among those who live in states where LGBT discrimination is culturally normative and institutionalized. Nevertheless, even for those within the same state or community, there is likely much variance in people's personal experiences with discrimination. In Study 3, we examine whether perceptions of the pervasiveness of LGBT discrimination relate to well-being, even (or especially) for people who have personally been discriminated against.

\section{Study 3}

We examine predictors of myriad indicators of mental and physical well-being in a racially diverse sample of lesbian women, gay men, and bisexual (LGB) individuals living in New York City, using a survey that assessed respondents' internalized homonegativity, whether they have personally experienced specific acts of discrimination, identification with the LGBT community, and more general perceptions of societal discrimination toward LGBT people. Based on previous research, we expect that internalized homonegativity and frequency of discriminatory experiences will be associated with poorer psychological and physical health (e.g., Herek et al., 2009). We also test whether group identification predicts better psychological and physical well-being, perhaps especially among those who have experienced discrimination firsthand.

Our focal hypothesis is that minimization of discrimination toward LGBT people will be an independent predictor of psychological, physical health, and mental health, above and beyond the (presumably negative) effects of having personally experienced discrimination, and the (presumably positive) effects of group identification. Because it is conceivable that group identification and perceptions of LGBT discrimination function differently for those who have versus have not personally experienced discrimination, we also examined whether experiences with discrimination (e.g., having been the target of discriminatory treatment) moderated the association between identification and discrimination perceptions with subjective well-being and mental and physical health.

\section{Method}

Participants and procedure. We used data collected from Project Stride, a study of identity, stress, and health among sexual minority individuals (Meyer, Frost, Narvaez, \& Dietrich, 2006). Data were collected between February 2004 and January 2005 from New York City residents, recruited from a variety of sampling venues (e.g., business establishments, social groups) and through snowball referrals (see Meyer et al., 2006, for more survey details).

After excluding respondents who reported that they were heterosexual $(n=128)$, data were available for 396 nonheterosexual respondents. A power analysis (Faul et al., 2007) indicated that this sample size is sufficient to detect a moderate effect size with a power of $99.99 \%$. Participants reported their age in categories, and $49.6 \%$ of the sample was below 30 years old. The majority $(54.1 \%)$ of respondents had a bachelor's degree or higher, and $50.0 \%$ were female. The sample was racially diverse by design, with $33.8 \%$ identifying as White, $33.1 \%$ as Black, and $33.1 \%$ as Latino/a. Participants identified as gay $(n=178)$, lesbian $(n=111)$, queer $(n=15)$, bisexual $(n=71)$, homosexual $(n=16)$, and "other LGBT" $(n=5)$.

For each of the following scales, the reliabilities were provided by the survey researchers, as the publicly available data do not include responses to individual items (see http:// www.columbia.edu/ im15/).

Predictor variables. Internalized homonegativity was assessed with nine items (e.g., "How often have you wished you weren't gay?"), with responses recorded on a 4-point scale $(\alpha=.84 ; M=1.41, S D=0.52)$. Participants' personal experience with discrimination was operationalized as the number of discriminatory incidents (e.g., being denied service) respondents reported having experienced because of their sexual orientation out of a possible eight $(M=2.37, S D$ $=2.07$ ).

Group identification was measured with an eight-item scale assessing how connected respondents felt to New York City's LGBT community on a 4-point scale $(\alpha=.80 ; M=$ $3.30, S D=0.52$ ). Minimization of discrimination toward LGBT people was assessed with six items tapping participants' expectations of rejection and discrimination of sexual minorities (e.g., "Most people would willingly accept [a gay man] as a close friend"). Items were rated on a 4-point scale $(\alpha=.88 ; M=2.07, S D=0.77)$.

Psychological health. The survey included six measures of psychological health. Social well-being was assessed with 15 items measuring respondents' perception of their social environment on a 7-point scale $(\alpha=.78 ; M=4.78, S D=$ 0.87). Psychological well-being was assessed with 18 items measuring self-acceptance, positive relations with others, purpose in life, and feelings of efficacy. Items were rated on a 7-point scale $(\alpha=.75 ; M=5.37, S D=0.76)$. Self-esteem was assessed with 10 items, answered on a 4-point scale $(\alpha$ $=.86 ; M=3.31, S D=0.56)$. Mastery was assessed with a seven-item scale that assessed the extent to which respondents felt they had control over certain aspects of their lives. Responses were given on a 3-point scale $(\alpha=.64 ; M=$ 2.63, $S D=0.31$ ). Depression was measured by the Center for Epidemiological Studies-Depression (CES-D), in which 
Table 5. Correlations Among Focal Variables (Study 3; $N=396$ ).

\begin{tabular}{|c|c|c|c|c|c|c|c|c|c|c|c|c|c|}
\hline & 1 & 2 & 3 & 4 & 5 & 6 & 7 & 8 & 9 & 10 & $\mathrm{II}$ & 12 & 13 \\
\hline \multicolumn{14}{|l|}{ Theoretical predictors } \\
\hline I. Discriminatory experiences & - & & & & & & & & & & & & \\
\hline 2. Minimization of discrimination & -.253 & - & & & & & & & & & & & \\
\hline 3. Internalized homonegativity & -.084 & -.117 & - & & & & & & & & & & \\
\hline $\begin{array}{l}\text { 4. Group identification } \\
\text { Outcome variables }\end{array}$ & .274 & -.063 & -.365 & - & & & & & & & & & \\
\hline 5. Social well-being & -.031 & .197 & -.237 & .314 & - & & & & & & & & \\
\hline 6. Psychological well-being & -.106 & .267 & -.301 & .179 & .532 & - & & & & & & & \\
\hline 7. Self-esteem & -.134 & .203 & $-.31 I$ & .153 & .490 & .717 & - & & & & & & \\
\hline 8. Mastery & -.110 & .234 & -.220 & .096 & .454 & .586 & .513 & - & & & & & \\
\hline 9. Depressive symptoms & .195 & -.244 & .224 & -.058 & -.412 & -.559 & -.549 & -.507 & - & & & & \\
\hline I0. Feeling of guilt & .159 & -.231 & .302 & -.099 & -.283 & -.403 & -.533 & -.290 & .432 & - & & & \\
\hline II. Anxiety disorder & .186 & -.169 & .157 & .042 & -.070 & -.198 & -.223 & -.041 & .213 & .226 & - & & \\
\hline 12. Drug/alcohol dependence & .082 & -.123 & .102 & -.092 & -.080 & -.163 & -.158 & -.056 & .147 & .136 & .127 & - & \\
\hline 13. Mental health illness & .120 & -.176 & .207 & -.048 & -.160 & -.263 & -.309 & -.150 & .322 & .330 & .619 & .230 & - \\
\hline 14. Physical health illness & .088 & -.079 & -.025 & .094 & -.058 & -.157 & -.182 & -.080 & .198 & .108 & .043 & .178 & .060 \\
\hline
\end{tabular}

Note. $p<.05$ for bolded coefficients.

respondents rated the frequency of 20 depressive symptoms on a 4-point scale $(\alpha=.92 ; M=0.71, S D=0.56)$. Guilt was assessed with four items measuring feelings of wrong-doing or personal blame within the past year, with responses rated on a 5-point scale $(\alpha=.69 ; M=2.28, S D=0.72)$.

Mental and physical health. The survey also included information on the respondents' mental and physical health history. Respondents participated in a structured diagnostic interview to assess both the lifetime and the 12-month prevalence of 17 psychiatric diagnoses and 22 physical illnesses. We only analyzed diagnoses that had 130 or more occurrences in this sample (10 events per predictor, as recommended by Concato, Peduzzi, Holford, \& Feinstein, 1995). We assessed the likelihood of (a) having received a lifetime diagnosis of any anxiety disorder $(n=172)$; (b) having received a lifetime diagnosis of having any drug or alcohol dependence $(n=149)$; and (c) having one or more psychiatric disorders in the last 12 months ("mental health illness"; $n=173$ ); and (d) if respondents had been diagnosed with three or more physical illnesses in their lifetime (two or fewer, $n=232$; three or greater, $n=164$ ).

Demographic variables. We adjusted for gender (female vs. male), race (Black and Latino compared with White), age category, age category squared, education (college degree or higher vs. otherwise), income (33-point scale), and religious service attendance (10-point scale). Political orientation was unavailable in this dataset. All predictor variables were mean-centered or dummy-coded.

\section{Results}

Bivariate correlations between the focal variables are listed in Table 5 (see supplementary materials for correlations with demographic variables).
Psychological health. We conducted six linear regression models, one for each of our subjective well-being dependent measures, with our demographic variables, internalized homonegativity, frequency of discriminatory experiences, group identification (and its interaction with discriminatory experiences), and minimization of discrimination (and its interactions with discriminatory experiences) predicting social well-being $\left(R^{2}=.23\right)$, psychological well-being $\left(R^{2}=\right.$ $.21)$, self-esteem $\left(R^{2}=.23\right)$, feelings of mastery $\left(R^{2}=.20\right)$, depressive symptoms $\left(R^{2}=.23\right)$, and feelings of guilt $\left(R^{2}=\right.$ .20).

As can be seen in Table 6, internalized homonegativity and the frequency of discriminatory experiences were both associated with worse well-being across all indicators. Group identification was significantly associated with social and psychological well-being, and feelings of mastery. There was a marginally significant relationship between group identification and self-esteem, and no relationship between group identification and feelings of guilt and depressive symptoms. None of these effects were moderated by the experience of discrimination.

As predicted, minimization of LGBT discrimination was positively and significantly associated with social and psychological well-being, self-esteem, and mastery, and negatively and significantly associated with depressive symptoms and guilt. For three indicators-social well-being, selfesteem, and depressive symptoms - a significant (or marginally significant) interaction with experiences of discrimination emerged. Analyses of the simple slopes showed that the relationship between minimization of societal LGBT discrimination and subjective well-being is stronger for those who have (vs. have not) experienced discrimination (see Figure 2a-2c). Specifically, among those who reported having infrequent discriminatory experiences $(-1 S D$, which is the point that corresponds to zero incidents of reported discrimination), 


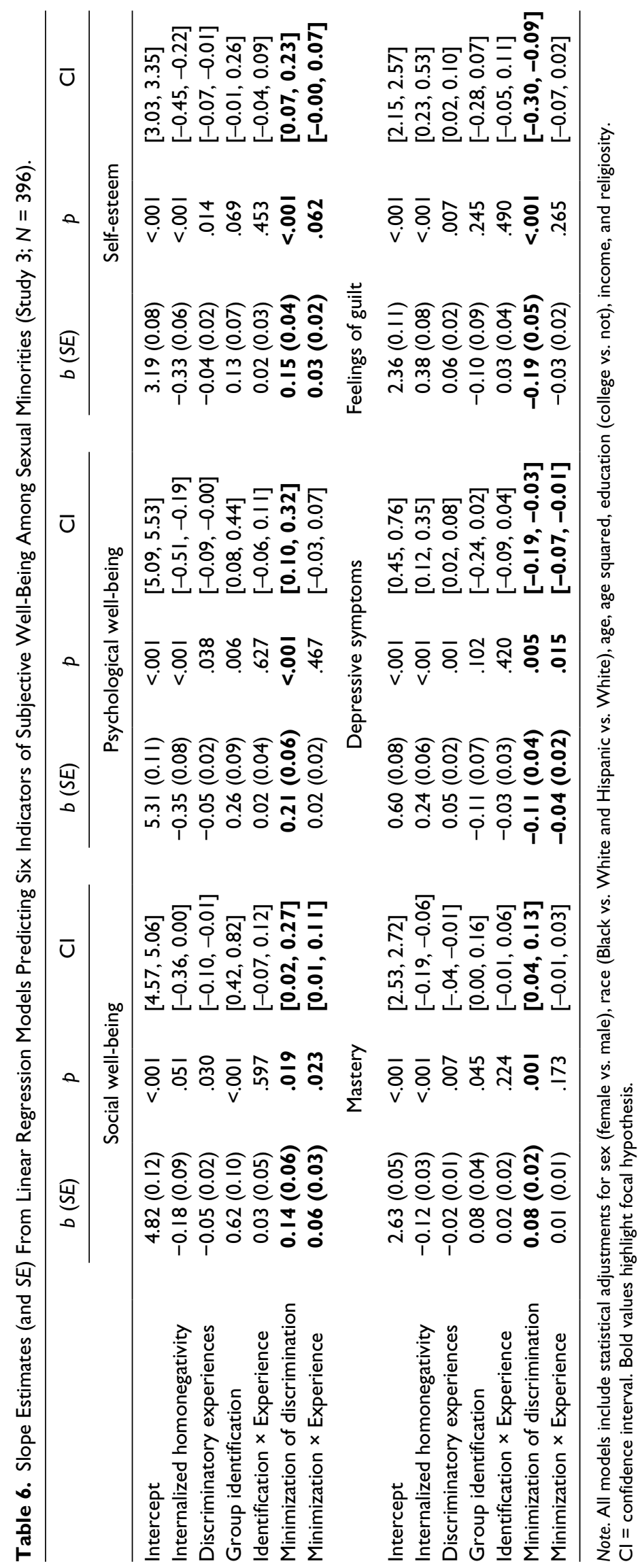




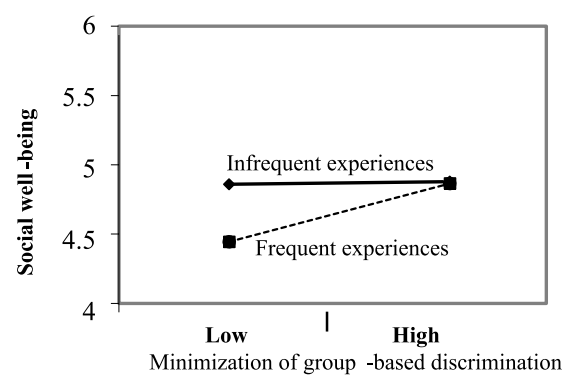

(a)

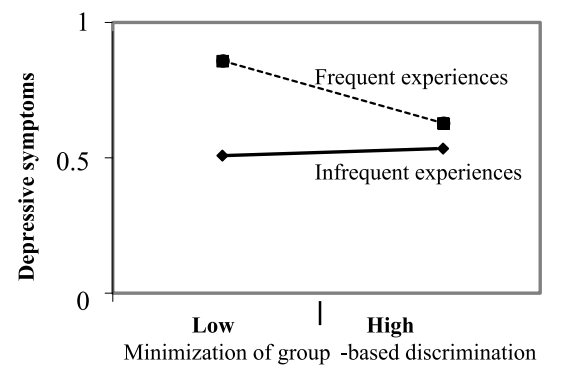

(c)

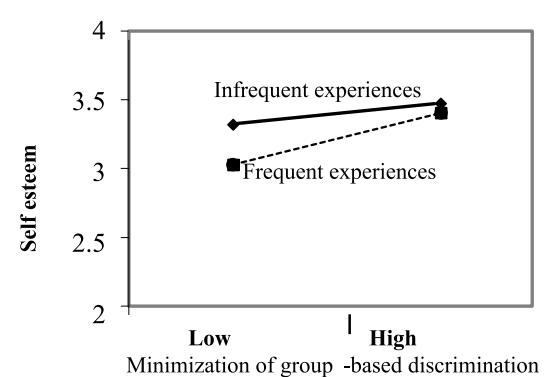

(b)

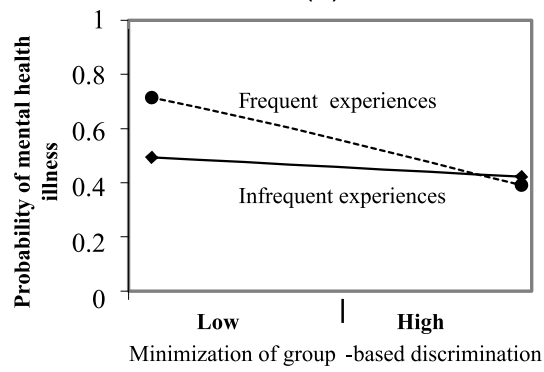

(d)

Figure 2. Minimization of societal LGBT discrimination ( $x$ axis) as a function of the frequency of experiencing discrimination for three measures of subjective well-being (a-c $y$ axis), and the probability of receiving a mental health diagnosis ( $d, y$ axis).

Note. LGBT = lesbian, gay, bisexual, and transgender.

minimization of discrimination was unassociated with social well-being, $b=.02, S E=0.08, p=.799$; depression, $b=-.03$, $S E=0.05, p=.614 ;$ and self-esteem, $b=.08, S E=0.05, p=$ .152. Among those who have experienced frequent discriminatory treatment $(+1 S D)$, these associations were much stronger: social well-being, $b=.27, S E=0.08, p=.001$; selfesteem, $b=.21, S E=0.06, p<.001$; and depression, $b=$ $-.20, S E=0.05, p<.001$.

Mental and physical health. We conducted four logistic regressions, using the same predictor variables, for the four dichotomous health variables (see Table 7). Results showed that internalized homonegativity was positively associated with the likelihood of diagnoses of anxiety disorders and other mental health problems, but, unexpectedly, it was unrelated to drug/alcohol dependency and physical health. We also found that frequency of experience with discrimination was significantly related to the likelihood of being diagnosed with an anxiety disorder or other mental health illness, but not related to substance dependency or physical health illness diagnoses.

There was no main effect of group identification on anxiety disorder diagnoses, but an interaction between discrimination experiences and group identification for mental health illness diagnoses emerged. Analysis of the simple slopes revealed that group identification is unrelated to the likelihood of having an anxiety disorder among those with high levels of discriminatory experience $(+1 S D), b=-.53, S E=$ $0.43, p=.218$; among those who have not experienced much discrimination $(-1 S D)$, group identification is related to an increased likelihood of being diagnosed with an anxiety disorder, $b=.83, S E=0.38, p=.026$. Group identification was also related to a lower likelihood of drug/alcohol dependence, but unrelated to other mental and physical health diagnoses.

As predicted, we find that minimization of discrimination toward the group is associated with reduced likelihood of health problems, including having been diagnosed with an anxiety disorder, drug or alcohol dependency, and a mental or physical health issue (see bolded lines in Table 7). To put these log-based numbers in a more intuitive context, the model reveals that all else being equal, ${ }^{2}$ an individual who maximally perceives discrimination (i.e., scoring " 1 " on the 1 to 4 scale) has a 68 probability of having an anxiety disorder, compared with a .42 probability for an individual who unequivocally denies discrimination (i.e., scoring " 4 " on the 1 to 4 scale); a .73 (vs. .45) probability of having alcohol or drug dependency; a .75 (vs. .39) probability of having had a mental health illness; and a .62 (vs. .31) probability of having had a physical health illness in his or her lifetime.

For mental health illness, the effect of minimization of discrimination toward the group was qualified by an interaction with having experienced discrimination (Figure 2d). Analysis of the simple slopes showed that among those with relatively little discriminatory experience $(-1 S D)$, perception of discrimination was unrelated to the likelihood of receiving a psychiatric diagnosis, $b=-.17, S E=0.23, p=.469$, whereas among those who have had experienced discrimination 
Table 7. Slope Estimates (and SE) From Logistic Regression Models Predicting Diagnosis of Four Mental and Physical Health Conditions Among Sexual Minorities (Study 3; $N=396$ ).

\begin{tabular}{|c|c|c|c|c|c|c|c|c|}
\hline & \multicolumn{4}{|c|}{ Anxiety disorder diagnosis } & \multicolumn{4}{|c|}{ Alcohol or drug dependency } \\
\hline & $b(S E)$ & $p$ & $\operatorname{Exp}(B)$ & $\mathrm{Cl}$ & $b(S E)$ & $p$ & $\operatorname{Exp}(B)$ & $\mathrm{Cl}$ \\
\hline Intercept & $0.05(0.34)$ & .893 & 1.05 & & $0.24(0.35)$ & .483 & 1.27 & \\
\hline Internalized homonegativity & $0.89(0.26)$ & .038 & 2.41 & {$[1.45,4.00]$} & $0.20(0.26)$ & .428 & 1.22 & {$[0.74,2.02]$} \\
\hline Discriminatory experiences & $0.15(0.07)$ & .020 & 1.17 & {$[1.02,1.33]$} & $0.11(0.07)$ & .087 & 1.12 & {$[0.98,1.28]$} \\
\hline Group identification & $0.15(0.29)$ & .598 & 1.16 & {$[0.66,2.03]$} & $-0.59(0.28)$ & .038 & 0.56 & {$[0.32,0.97]$} \\
\hline Identification $\times$ Experience & $-0.33(0.14)$ & .017 & 0.72 & {$[0.55,0.94]$} & $-0.08(0.13)$ & .550 & 0.92 & {$[0.7 \mathrm{I}, \mathrm{I} .20]$} \\
\hline Minimization of discrimination & $-0.36(0.18)$ & .038 & 0.70 & {$[0.49,0.98]$} & $-0.41(0.18)$ & .019 & 0.66 & {$[0.47,0.93]$} \\
\hline \multirow[t]{2}{*}{ Minimization $\times$ Experience } & $-0.05(0.08)$ & .523 & 0.952 & {$[0.82,1.1 \mathrm{I}]$} & $0.07(0.07)$ & .345 & 1.07 & {$[0.93,1.24]$} \\
\hline & \multicolumn{4}{|c|}{ Mental health illness } & \multicolumn{4}{|c|}{ Physical health illness } \\
\hline Intercept & $0.10(0.35)$ & .773 & 1.11 & & $-0.33(0.35)$ & .343 & 0.72 & \\
\hline Internalized homonegativity & $1.06(0.27)$ & $<.001$ & 2.90 & {$[1.71,4.91]$} & $0.02(0.26)$ & .944 & 1.02 & {$[0.61,1.69]$} \\
\hline Discriminatory experiences & $0.10(0.07)$ & .132 & 1.11 & {$[0.97,1.26]$} & $0.09(0.07)$ & .167 & 1.10 & {$[0.96,1.25]$} \\
\hline Group identification & $-0.35(0.29)$ & .220 & 0.71 & {$[0.40,1.23]$} & $-0.01(0.29)$ & .974 & 0.99 & {$[0.57,1.73]$} \\
\hline Identification $\times$ Experience & $-0.19(0.14)$ & .185 & 0.83 & {$[0.62,1.09]$} & $-0.14(0.14)$ & .874 & 0.87 & {$[0.67,1.14]$} \\
\hline Minimization of discrimination & $-0.52(0.18)$ & .004 & 0.60 & {$[0.42,0.85]$} & $-0.42(0.18)$ & .019 & 0.66 & {$[0.47,0.93]$} \\
\hline Minimization $\times$ Experience & $-0.17(0.08)$ & .042 & 0.84 & {$[0.72,0.99]$} & $-0.02(0.08)$ & .773 & 0.98 & {$[0.85,1.13]$} \\
\hline
\end{tabular}

Note. All models include statistical adjustments for sex (female vs. male), race (Black vs. White and Hispanic vs. White), age, age squared, education (college vs. not), income, and religiosity. Bold values highlight focal hypothesis.

$(+1 S D)$, those who minimized discrimination toward the group were less likely to have been diagnosed with a mental health problem, $b=-.87, S E=0.27, p=.001$.

\section{Discussion}

The results from this study showed that the relationship between minimization of discrimination toward the group and subjective, physical, and mental well-being is remarkably consistent. All else being equal, sexual minorities who reject the notion that their group is socially stigmatized are happier, healthier, more confident and efficacious, feel less guilty, report fewer depressive symptoms, and are less likely to struggle with substance abuse or other mental health issues than those who believe that other members of their group are targets of discrimination. This was true regardless of whether or not the respondent reported having personally experienced discriminatory treatment because of his or her sexual orientation. Indeed, for some indicators-specifically, better social well-being, higher self-esteem, fewer depressive symptoms, and decreased likelihood of mental health illness - we found that the minimization of societal discrimination is associated with positive outcomes especially for those who report having been a victim of discrimination. This, along with the effects on BMI from Study 2, is consistent with the proposition that system justification (at least, in the form of denial) can serve to buffer individuals' well-being even (or especially) in the face of injustice. Presumably, those with high needs for system justification view discriminatory encounters as unrepresentative of the society at large, perpetrated by few "bad apples."

Consistent with Study 1 and previous research, we found that internalization of stigma is associated with poorer psychological well-being and worse mental health (including anxiety disorders). Results also showed that group identification was associated with better psychological well-being, and this was true regardless of whether or not the individual had previously experienced discrimination. With the exception of substance abuse problems, however, there was no reliable main effect between group identification and medical diagnoses or with depressive symptoms. Unexpectedly, we found that group identification is positively related to risk of having an anxiety disorder among those with infrequent discrimination experiences (but unrelated among those who have frequently experienced discrimination).

The fact that minimization of group discrimination predicts actual diagnoses of mental and physical illnesses and substance abuse makes a "social desirability" explanation for the association between minimization of discrimination and well-being less tenable, insofar as actual diagnoses are more objective measures and are less subject to motivated presentation in self reports. We did, however, rely on participants' self-reports of discriminatory experiences. Presumably, those who tend to minimize group-based discrimination in general are also less likely to identify experiences as discriminatory (although these variables were only modestly correlated; see Table 5). Thus, this is a rather conservative test of our hypothesis. 


\section{General Discussion}

Results across three studies offer empirical support for the proposition that minimizing the extent to which their group is discriminated against serves a palliative function for members of LGBT communities. Study 1 showed that minimization of discrimination against gay and bisexual men was associated with better subjective well-being and this was mediated by perceived system fairness. In Studies 2 and 3, using highly diverse samples of LGBT individuals, we find that those who minimize the extent to which their group is discriminated against are healthier and happier across myriad indicators of psychological and physical health. We further show that these effects held regardless of the level of LGBT acceptance in the environment (Study 2), and regardless of whether the individual had personally been the target of sexual prejudice (Study 3). In fact, for some indicatorsspecifically, BMI in Study 2 and social well-being, selfesteem, lower depressive symptoms, and reduced likelihood of mental health illness in Study 3 - the effect of minimizing discrimination was especially strong among those for whom the threat of personally experiencing discrimination was highest. In sum, the evidence from our studies suggests that system justification (at least in the form of discrimination minimization) provides remarkably consistent relief from the pervasive effects of injustice. The "positive illusions" that promote well-being for the individual can lead to a negative reality for society.

Of course, the evidence presented here is correlational, and thus, we can make no claims about the direction of causality. Evidence suggests that reports of experiences of discrimination lead to worse well-being, but not the other way around. For example, in a sample of nearly 800 African Americans, those who reported having been (vs. not been) "treated badly because of [their] race in the past month" reported higher levels of psychological distress 1 year later, but psychological distress during the first year did not predict reports of discrimination in the follow-up year (Brown et al., 2000). Furthermore, experiencing discrimination has been directly associated with so-called "silent diseases," that is, unhealthy pre-clinical endpoints (such as inflammation and hypertension) that link to more serious diseases down the road (Lewis, Cogburn, \& Williams, 2015).

As for the relationship between perception of discrimination toward the group and well-being, it could be, as we posit, that minimizing the disadvantage associated with being an LGBT individual serves to buffer against the otherwise negative effects of perceiving the world as unjust. Alternatively, it is possible that those who are happier are somehow more apt to ignore evidence of system-level discrimination. This alternative is consistent with the concept of depressive realism, which is the theory that individuals with greater (vs. fewer) depressive symptoms are often more accurate at judging certain situations (Bortolotti \& Antrobus, 2015). In either case, experimental manipulations of discrimination perceptions are likely insufficient to capture this process, which undoubtedly unfolds over a long period of time. There is reason to believe that the short- versus long-term effects of perceiving discrimination are very different (e.g., Major et al., 2002), which highlights the need for extensive longitudinal data.

Nevertheless, these findings illuminate a disturbing phenomenon - namely, those who do not acknowledge systemlevel problems enjoy better positive mental and physical health (see also Napier \& Jost, 2008), even when they are members of groups that are overtly devalued and culturally and legally oppressed. This highlights the important point that well-being among members of stigmatized groups may not always be an indicator of progress, but in fact could be a symptom of justifying inequality. Moreover, the association between minimization of discrimination and well-being suggests that the happiest and healthiest group members - who are presumably the best psychologically and physically suited to fight for social change- might be the least likely to do so.

\section{Connections and Contributions to the Literature}

Many studies have documented the connection between system-justifying motivations and the denial of the existence of cultural and institutional discrimination among members of privileged groups (e.g., the denial of racial discrimination is pervasive among Whites; Neville, Awad, Brooks, Flores, \& Bluemel, 2013; Sears \& Henry, 2005). This work has often highlighted the group disparities in the perception of discrimination - that is, members of advantaged (vs. disadvantaged) groups are much more likely to dismiss discrimination as an explanation for unequal outcomes (Napier, Mandisodza, Andersen, \& Jost, 2006). Despite these group-level differences, there is variance in the extent to which members of low status groups acknowledge discrimination as a problem that their group must face (Seller \& Shelton, 2003; Stephens \& Levine, 2011).

Beyond providing a veneer of justice, minimizing the extent of the group's disadvantage could serve to psychologically elevate the group's status. This suggests, too, that researchers should not be too quick to conclude that systemjustifying motivations are lower (or absent) among members of disadvantaged groups based on mean group differences (or a lack thereof, for example, Brandt, 2013). The extent to which system-legitimating beliefs are tenable is contextually bound by people's reality, but even mild justifications for inequality (especially when they come from the stigmatized group) could substantially boost perceived legitimacy.

On that point, we refer to this process as "minimization" (and not "denial") of group discrimination because it seems unlikely that many LGBT individuals would flat-out reject the notion that their group is a target of prejudice. That said, the number of participants indicating disagreement with the notion that their group is the target of discrimination was not trivial-for example, $21.1 \%$ of participants in Study 1 
"agreed" (slightly to strongly) that "homosexuality is no longer a problem in the United States," an additional 17.3\% "neither agreed nor disagreed," and approximately $26.3 \%$ ( $n$ $=1,103$ ) of respondents in Study 2 "agreed" that "homophobia is not a problem within my racial or ethnic community." These figures are striking when one considers, for instance, that over $55 \%$ of gay men and lesbian women in the United States report having been verbally harassed because of their sexual orientation (Katz-Wise \& Hyde, 2012).

Our data also highlight ingroup identification as another predictor of well-being among LGBT individuals. Identification was associated with psychological well-being, for the most part, and reduced likelihood of having an alcohol or drug dependence (Study 3), but it was not a predictor of physical health (Studies 2 and 3), body weight (Study 2), or mental health illness (Study 3). Thus, our studies are consistent with the proposition that social identities can serve as a "social cure" (Jetten, Haslam, \& Haslam, 2012), even for members of stigmatized groups, although the effects appear to be limited to measures of subjective well-being.

Of course, it is possible that identification with other (nonLGBT relevant) groups also promotes well-being and health in this population. However, the minimization of discrimination might be a consequence of (or strategy for) maintaining identification with other groups, especially those that are heteronormative or even hostile toward LGBT equality. Research has demonstrated that members of stigmatized groups who make accusations of (Kaiser \& Miller, 2001) or confront (Czopp \& Monteith, 2003) prejudice are disliked and face backlash, and thus members of stigmatized groups might minimize group-based discrimination to facilitate more harmonious relationships with others. It seems possible that the minimization of group discrimination is prevalent among members of stigmatized groups who maintain identification with multiple (nonstatus relevant) groups, a factor that is associated with well-being (Jetten et al., 2012).

Research has illustrated that the relationship between identification (with status-irrelevant groups) and health is accounted for by enhanced perceptions of personal control (Greenaway et al., 2015). It is conceivable that identification was not associated with health in our studies because identification with a group that has a history of societal devaluation (such as LGBT) is more complicated, and perhaps less likely to provide a sense of personal agency (see also Crabtree, Haslam, Postmes, \& Haslam, 2010; Kellezi \& Reicher, 2012). At the same time, some work suggests that group identification among members of disadvantaged groups enhances perceptions of the group agency-that is, belief that the group is effectively able to fight discrimination through collective action - and this, in turn, is associated with better subjective well-being (Outten \& Schmitt, 2015). Thus, one intervention that might allow members of stigmatized groups to acknowledge inequality without negatively impacting their mental health may be highlighting the possibility of change through collective action.

\section{Social Cure Versus Palliative Relief}

In medicine, the most difficult decision is choosing whether to continue treatment or to minimize pain - that is, to shift from a curative focus to a palliative one. By adding a system justification perspective, we illuminate another pathway to the maintenance of well-being in stigmatized populations, and one that might be particularly troublesome. While the minimization of group-based discrimination allows inequality to fester, its system-justifying function may be the morphine that reduces its sting.

Although we have focused on how system justification and group identification relate to small boosts in mental health for LGBT individuals, we do not want to minimize the power of stigmatization to strip people of their sense of meaning and purpose in life. To take just one example, LGBT youth are 4 times more likely to commit suicide than their heterosexual peers (Centers for Disease Control and Prevention, 2011). Clearly, the real remedy that is needed is the antidote to intolerance. In the meantime, the results from our studies illuminate the complicated ways that sexual minorities try to negotiate a sense of self-worth in the face of social and political devaluation. By minimizing (or even denying) widespread (and legally sanctioned) discrimination, members of stigmatized groups may find happiness and health, but are simultaneously supporting the system that stigmatized them in the first place.

\section{Declaration of Conflicting Interests}

The author(s) declared no potential conflicts of interest with respect to the research, authorship, and/or publication of this article.

\section{Funding}

The author(s) received no financial support for the research, authorship, and/or publication of this article.

\section{Notes}

1. Participants were recruited to complete a 30-s demographic survey. We invited those who indicated that they were men who sexually prefer men to complete our survey.

2. Based on the reference groups, these estimates refer to a White male in his early $30 \mathrm{~s}$, without a college degree, and with income and a level of religiosity equal to the sample average, with an average level of internalized homonegativity, group identification, and frequency of discriminatory experiences.

\section{Supplemental Material}

Supplementary material is available online with this article.

\section{References}

Bahamondes-Correa, J. (2016). System justification's opposite effects on psychological wellbeing: Testing a moderated mediation model in a gay men and lesbian sample in Chile. Journal of Homosexuality, 63, 1537-1555. 
Battle, J., Pastrana, A. Jr., \& Daniels, J. (2013). Social Justice Sexuality Survey: The executive summary. New York, NY. Available from http://socialjusticesexuality.com/

Bortolotti, L., \& Antrobus, M. (2015). Costs and benefits of realism and optimism. Current Opinion in Psychiatry, 28, 194-198.

Bourguignon, D., Seron, E., Yzerbyt, V., \& Herman, G. (2006). Perceived group and personal discrimination: Differential effects on personal self-esteem. European Journal of Social Psychology, 36, 773-789.

Brandt, M. J. (2013). Do the disadvantaged legitimize the social system? A large-scale test of the status-legitimacy hypothesis. Journal of Personality and Social Psychology, 104, 765-785.

Branscombe, N. R., Schmitt, M. T., \& Harvey, R. D. (1999). Perceiving pervasive discrimination among African Americans: Implications for group identification and well-being. Journal of Personality and Social Psychology, 77, 135-149.

Brown, T. N., Williams, D. R., Jackson, J. S., Neighbors, H. W., Torres, M., Sellers, S. L., \& Brown, K. T. (2000). Being black and feeling blue: The mental health consequences of racial discrimination. Race and Society, 2, 117-131.

Centers for Disease Control and Prevention. (2011). Sexual identity, sex of sexual contacts, and health-risk behaviors among students in grades 9-12: Youth risk behavior surveillance. Atlanta, GA: U.S. Department of Health and Human Services. Retrieved from https://www.cdc.gov/mmwr/volumes/65/ss/ ss6509a1.htm

Centers for Disease Control and Prevention. (2015). Behavioral risk factor surveillance system. Atlanta, GA: U.S. Department of Health and Human Services. Retrieved from https://www. cdc.gov/brfss/

Cochran, S. D., Sullivan, J. G., \& Mays, V. M. (2003). Prevalence of mental disorders, psychological distress, and mental health services use among lesbian, gay, and bisexual adults in the United States. Journal of Consulting and Clinical Psychology, 71, 53-61.

Concato, J., Peduzzi, P., Holford, T. R., \& Feinstein, A. R. (1995). Importance of events per independent variable in proportional hazards analysis I. Background, goals, and general strategy. Journal of Clinical Epidemiology, 48, 1495-1501.

Crabtree, J. W., Haslam, S. A., Postmes, T., \& Haslam, C. (2010). Mental health support groups, stigma, and self-esteem: Positive and negative implications of group identification. Journal of Social Issues, 66, 553-569.

Crosby, F. J. (1984). The denial of personal discrimination. American Behavioral Scientist, 27, 371-386.

Czopp, A. M., \& Monteith, M. J. (2003). Confronting prejudice (literally): Reactions to confrontations of racial and gender bias. Personality and Social Psychology Bulletin, 29, 532-544.

Dalbert, C. (2001). Critical Issues in Social Justice. The justice motive as a personal resource: Dealing with challenges and critical life events. Springer, New York, NY.

Dalbert, C., \& Filke, E. (2007). Belief in a personal just world, justice judgments, and their functions for prisoners. Criminal Justice and Behavior, 34, 1516-1527.

Faul, F., Erdfelder, E., Lang, A.-G., \& Buchner, A. (2007). G*Power 3: A flexible statistical power analysis program for the social, behavioral, and biomedical sciences. Behavior Research Methods, 39, 175-191.

Feldman-Barrett, L., \& Swim, J. (1998). Appraisals of prejudice and discrimination. In J. K. Swim \& C. Stangor (Eds.),
Prejudice: The target's perspective (pp. 11-36). San Diego, CA: Academic Press.

Fingerhut, A. W., Peplau, L. A., \& Gable, S. L. (2010). Identity, minority stress and psychological well-being among gay men and lesbians. Psychology and Sexuality, 1, 101-114.

Gallup Healthways Well-Being Index. (2014). Methodology report for indexes. Retrieved from http://www.gallup.com/ poll/125066/State-States.aspx

Greenaway, K. H., Haslam, S. A., Cruwys, T., Branscombe, N. R., Ysseldyk, R., \& Heldreth, C. (2015). From "we" to "me": Group identification enhances perceived personal control with consequences for health and well-being. Journal of Personality and Social Psychology, 109, 53-74.

Hatzenbuehler, M. L. (2014). Structural stigma and the health of lesbian, gay, and bisexual populations. Current Directions in Psychological Science, 23, 127-132.

Herek, G. M., Gillis, J. R., \& Cogan, J. C. (2009). Internalized stigma among sexual minority adults: Insights from a social psychological perspective. Journal of Counseling Psychology, 56, 32-43.

Jerald, M. C., Cole, E. R., Ward, L. M., \& Avery, L. R. (2017). Controlling images: How awareness of group stereotypes affects black women's well-being. Journal of Counseling Psychology, 64, 487-499.

Jetten, J., Haslam, C. \& Haslam, S. A. (Eds.). (2012). The social cure: Identity, health and well-being. Chicago, IL: Psychology Press.

Jost, J. T., Banaji, M. R., \& Nosek, B. A. (2004). A decade of system justification theory: Accumulated evidence of conscious and unconscious bolstering of the status quo. Political Psychology, 25, 881-919.

Jost, J. T., \& Kay, A. C. (2005). Exposure to benevolent sexism and complementary gender stereotypes: Consequences for specific and diffuse forms of system justification. Journal of Personality and Social Psychology, 88, 498-509.

Kaiser, C. R., \& Miller, C. T. (2001). Stop complaining! The social costs of making attributions to discrimination. Personality and Social Psychology Bulletin, 27, 254-263.

Katz-Wise, S. L., \& Hyde, J. S. (2012). Victimization experiences of lesbian, gay, and bisexual individuals: A meta-analysis. Journal of Sex Research, 49, 142-167.

Kellezi, B., \& Reicher, S. (2012). Social cure or social curse? The psychological impact of extreme events during the Kosovo conflict. In J. Jetten, C. Haslam, \& A. Haslam (Eds.), The social cure: Identity, health and well-being (pp. 217-233). Hove, UK: Psychology Press.

Kertzner, R. M., Meyer, I. H., Frost, D. M., \& Stirratt, M. J. (2009). Social and psychological Weil-Being in lesbians, gay men, and bisexuals: The effects of race, gender, age, and sexual identity. American Journal of Orthopsychiatry, 79, 500-510.

Lerner, M. J. (1980). The belief in a just world. New York, NY: Plenum.

Lewis, T. T., Cogburn, C. D., \& Williams, D. R. (2015). Selfreported experiences of discrimination and health: Scientific advances, ongoing controversies, and emerging issues. Annual Review of Clinical Psychology, 11, 407-440.

Lick, D. J., Durso, L. E., \& Johnson, K. L. (2013). Minority stress and physical health among sexual minorities. Perspectives on Psychological Science, 85, 521-548.

Lipkus, I. M., \& Siegler, I. C. (1993). The belief in a just world and perceptions of discrimination. The Journal of Psychology, 127, 465-474. 
Major, B., Gramzow, R. H., McCoy, S. K., Levin, S., Schmader, T., \& Sidanius, J. (2002). Perceiving personal discrimination: The role of group status and legitimizing ideology. Journal of Personality and Social Psychology, 82, 269-282.

McLean, H. V. (1946). Psychodynamic factors in racial relations. The Annals of the American Academy of Political and Social Science, 244, 159-166.

Meyer, I. H. (2003). Prejudice, social stress, and mental health in lesbian, gay, and bisexual populations: Conceptual issues and research evidence. Psychological Bulletin, 129, 674-697.

Meyer, I. H., Frost, D. M., Narvaez, R., \& Dietrich, J. H. (2006). Project Stride methodology and technical notes. Retrieved from http://www.columbia.edu/ im15/method/stridemethod.pdf

Napier, J. L., \& Jost, J. T. (2008). Why are conservatives happier than liberals? Psychological Science, 19, 565-572.

Napier, J. L., Mandisodza, A., Andersen, S. M., \& Jost, J. T. (2006). System justification in responding to the poor and displaced in the aftermath of Hurricane Katrina. Analyses of Social Issues and Public Policy, 6, 57-73.

Napier, J. L., Thorisdottir, H., \& Jost, J. T. (2010). The joy of sexism? A multinational investigation of hostile and benevolent justifications for gender inequality and their relations to subjective well-being. Sex Roles, 62, 405-419.

Neville, H. A., Awad, G. H., Brooks, J. E., Flores, M. P., \& Bluemel, J. (2013). Color-blind racial ideology: Theory, training, and measurement implications in psychology. American Psychologist, 68, 455-466.

Norton, M. I., \& Ariely, D. (2011). Building a better AmericaOne wealth quintile at a time. Perspectives on Psychological Science, 6, 9-12.

Ogden, C. L., Carroll, M. D., Fryar, C. D., \& Flegal, K. M. (2015). Prevalence of obesity among adults and youth: United States, 2011-2014. NCHS Data Brief, 219, 1-8.

Outten, H. R., \& Schmitt, M. T. (2015). The more "intergroup" the merrier? The relationship between ethnic identification, coping options, and life satisfaction among South Asian Canadians. Canadian Journal of Behavioural Science, 47, 12-20.

Pacilli, M. G., Taurino, A., Jost, J. T., \& van der Toorn, J. (2011). System justification, right-wing conservatism, and internalized homophobia: Gay and lesbian attitudes toward same-sex parenting in Italy. Sex Roles, 65, 580-595.

Paradies, Y. (2006). A systematic review of empirical research on self-reported racism and health. International Journal of Epidemiology, 35, 888-901.

Pascoe, E. A., \& Smart-Richman, L. (2009). Perceived discrimination and health: A meta-analytic review. Psychological Bulletin, 135, 531-554.
Potok, M. (2016). QUACKS “Conversion Therapists," the anti$L G B T$ right, and the demonization of homosexuality. Southern Poverty Law Center. Retrieved from https://www.splcenter. org/20160525/quacks-conversion-therapists-anti-lgbt-rightand-demonization-homosexuality

Sandfort, Th.G.M. (1997). Samen of apart.Wat homoseksuele mannen en lesbische vrouwen beweegt [Together or separate. Aspects that affect gay men and lesbian women]. Utrecht, The Netherlands: Department of Gay and Lesbian Studies, Utrecht University.

Schmitt, M. T., Branscombe, N. R., Kobrynowicz, D., \& Owen, S. (2002). Perceiving discrimination against one's gender group has different implications for well-being in women and men. Personality and Social Psychology Bulletin, 28, 197-210.

Schmitt, M. T., Branscombe, N. R., Postmes, T., \& Garcia, A. (2014). The consequences of perceived discrimination for psychological well-being: A meta-analytic review. Psychological Bulletin, 140, 921-948.

Sears, D. O., \& Henry, P. J. (2005). Over thirty years later: A contemporary look at symbolic racism. Advances in Experimental Social Psychology, 37, 95-150.

Sellers, R. M., \& Shelton, J. N. (2003). The role of racial identity in perceived racial discrimination. Journal of Personality and Social Psychology, 84, 1079-1092.

Stephens, N. M., \& Levine, C. S. (2011). Opting out or denying discrimination? How the framework of free choice in American society influences perceptions of gender inequality. Psychological Science, 22, 1231-1236.

Taylor, S. E., \& Brown, J. D. (1988). Illusion and well-being: A social psychological perspective on mental health. Psychological Bulletin, 103, 193-210.

Tilcsik, A. (2011). Pride and prejudice: Employment discrimination against openly gay men in the United States. American Journal of Sociology, 117, 586-626.

Wakslak, C., Jost, J. T., Tyler, T. R., \& Chen, E. (2007). Moral outrage mediates the dampening effect of system justification on support for redistributive social policies. Psychological Science, 18, 267-274.

Waters, E., Jindasurat, C., \& Wolfe, C. (2016). Lesbian, gay, bisexual, transgender, queer and HIV-affected hate violence in 2015 (National Coalition of Anti-violence Programs). Retrieved from https://avp.org/wp-content/uploads/2017/04/ncavp_hvreport_2015_final.pdf

Williams, D. R., Neighbors, H. W., \& Jackson, J. S. (2003). Racial/ ethnic discrimination and health: Findings from community studies. American Journal of Public Health, 93, 200-208. 